\title{
Experimental Study on Progressive Collapse Performance of Frame with Specially Shaped Columns Subjected to Middle Column Removal
}

\author{
Tiecheng Wang, ${ }^{1,2}$ Qingwei Chen, ${ }^{1}$ Hailong Zhao, ${ }^{1,2}$ and Lei Zhang ${ }^{1}$ \\ ${ }^{1}$ School of Civil Engineering, Tianjin University, Tianjin 300072, China \\ ${ }^{2}$ Key Laboratory of Coast Civil Structure Safety, Tianjin University, Ministry of Education, Tianjin 300072, China
}

Correspondence should be addressed to Hailong Zhao; hlongzhao_tju@163.com

Received 13 May 2015; Revised 27 August 2015; Accepted 31 August 2015

Academic Editor: Gilbert-Rainer Gillich

Copyright (C) 2016 Tiecheng Wang et al. This is an open access article distributed under the Creative Commons Attribution License, which permits unrestricted use, distribution, and reproduction in any medium, provided the original work is properly cited.

\begin{abstract}
A static collapse experiment was carried out to study the progressive collapse resistance and failure mechanisms and modes of a 1/3-scale, $2 \times 3$-bay, and 2-story reinforced concrete frame with specially shaped columns subjected to middle column removal. A vertical concentrated load was applied to the top of the middle column to simulate the gravity load of the upper floors and the applied load was statically transmitted to the adjacent columns through the frame beams and slabs during the collapse process. The frame collapsed when the vertical displacement of the joint on the top of the failed column reached $170 \mathrm{~mm}$ due to the failure of beam-column joints. Based on the experimental phenomena and results, the progressive collapse-resistant behavior of the model frame is analyzed and the redistribution and transition of the load resisting mechanisms are discussed. It is concluded that the redistribution of internal force was mainly realized via the beam resisting mechanism and the compressive arch action in beams played an important role to improve the collapse-resistant capacity.
\end{abstract}

\section{Introduction}

Progressive collapse is defined as the spread of an initial local failure from element to element eventually resulting in collapse of an entire structure or a disproportionately large part of it [1]. Many practicing engineers and academic researchers have been engaged in the prevention of progressive collapse since the partial collapse of the Ronan Point apartment building in 1968. In particular, widespread concerns of progressive collapse of structures have accelerated since the 9/11 event leading to the collapse of the New York World Trade Center twin towers [2]. In recent years, the development of analysis methods for evaluating the progressive collapse potential of an existing or new building has been an imperative subject. Some nations are investigating progressive collapse resistance, and a series of design specifications and guidelines have been published [3-5]. One approach to evaluate progressive collapse of structures is to study the effects of instantaneous removal of a load-bearing element such as a column. A number of experimental studies have been carried out to investigate progressive collapse performance of RC structures subjected to column removal. Sasani and Kropelnicki [6] carried out experiments to study the behavior of a scaled model of a continuous perimeter beam in a RC frame structure following removal of a supporting column. Sasani et al. [7] evaluated potential progressive collapse of an actual 10-story reinforced concrete structure following the explosion of an exterior column. Yi et al. [8] carried out a static experimental study of a three-story RC frame structure to investigate progressive failure due to the loss of a lower story column. A number of experimental studies also have been carried out to investigate large-deformation behavior of reinforced concrete beamcolumn assemblies. Kim and $\mathrm{Yu}$ [9] indicated that seismically designed RC moment frames could resist progressive collapse by activation of beam catenary force at large displacement. Su et al. [10] indicated a significant enhancement of the beam flexural strength because of the compressive arch action, which could be influenced by flexural reinforcement ratio and beam span-depth ratio. Yu and Tan [11] investigated the effect 


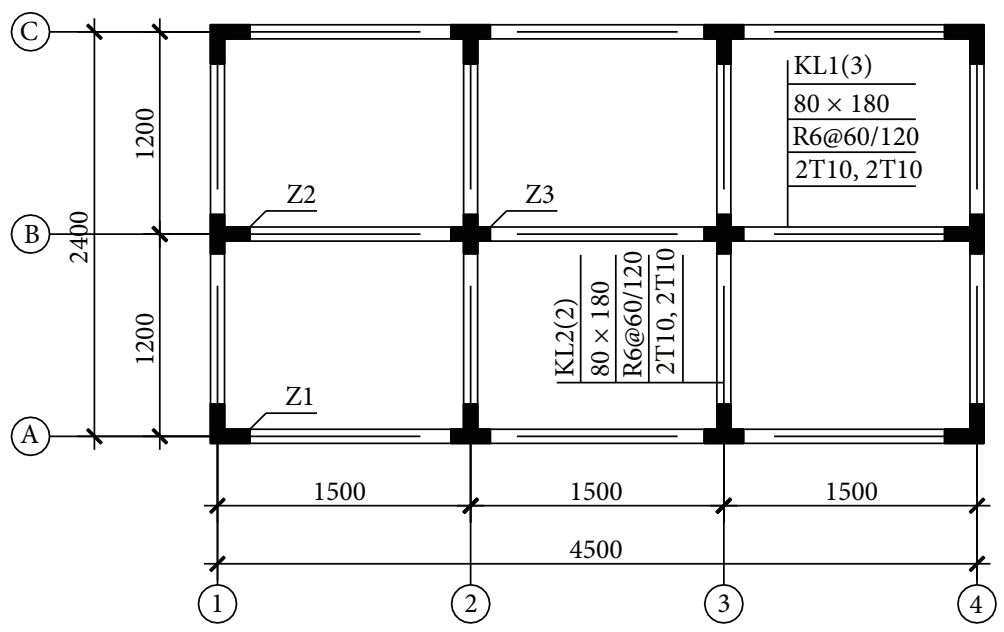

FIGURE 1: Dimensions of model frame.

of seismic detailing on structural behavior under a middle column removal scenario. Yap and Li [12] tested two series of specimens to study the structural behavior of exterior beamcolumn subassemblies for progressive collapse, one representing as-built design and the other representing improved design.

Reinforced concrete frame with specially shaped columns offers advantages such as avoiding prominent corners in a room, increasing usable floor area, and reducing dead load of structure combined with the use of lightweight material filler walls. However, specially shaped columns are weak at bearing capacity and seismic performance owing to the relatively smaller cross section area. Experiments on reinforced concrete frames with specially shaped columns and components had been carried out in recent years to study their seismic performance $[13,14]$. However, studies on progressive collapse performance of structures are mainly concentrated on frame structures with rectangular columns and rarely involve frame structures with specially shaped columns. The frame structures with specially shaped columns are widely adopted in residential structures which will cause serious losses of lives and properties once collapse occurs. Therefore, it is necessary to conduct a further research on the progressive collapse performance of frames with specially shaped columns. A static experiment of a 1/3-scale, $2 \times 3$ bay, and 2-story RC frame with specially shaped columns was carried out to study the collapse-resistant behavior, redistribution of internal forces, and failure modes of RC frame with specially shaped columns following the loss of one column on the first story.

\section{Design of Testing Model Frame}

In order to study the progressive collapse performance and failure mechanism of RC frame with specially shaped columns when the vertical load-bearing component failed, a 1/3-scale, $2 \times 3$-bay, 2 -story RC frame was designed and manufactured as a reduced order model of a prototype fourstory RC frame structure with specially shaped columns in accordance with requirements of concrete design code [15] and technical specification for concrete structures with specially shaped columns of China [16]. The design also satisfied the Chinese seismic design code for the category VII intensity, or regions with moderate seismicity. The geometrical dimensions of the model frame are shown in Figure 1 and the reinforcement details of beams, columns, and beamcolumn joints at the top floor are provided in Figures 2 and 3, respectively (all dimensions are in $\mathrm{mm}$ ). The story height was $1000 \mathrm{~mm}$, and the thickness of slab was $50 \mathrm{~mm}$. T8 steel bars were orthogonally arranged inside the slab with the interval of $150 \mathrm{~mm}$. During the concrete casting process of the model frame, B1 column at the first story designed as the failed column was substituted by a steel tube with welded spherical joint to support the superstructure. The model frame was built on a foundation beam that was fixed on the strong reaction floor of the laboratory by anchor bolts. Lap splices, anchorage of steel bars, and spacing of stirrups were strictly in accordance with Chinese code requirements $[15,16]$. Picture of completed model structure is shown in Figure 4.

The strength grades of longitudinal bars and stirrups used in beams and columns were $400 \mathrm{MPa}$ and $300 \mathrm{MPa}$, respectively. $400 \mathrm{MPa}$ reinforcement was used in the slabs. C40 concrete was used for the model frame. The measured values of mechanical properties of reinforcing bars and concrete used to fabricate the specimen are shown in Table 1. The average compressive strength of concrete by cubic tests was $42.3 \mathrm{MPa}$ at 28 days, which is equal to $33.84 \mathrm{MPa}$ by cylinder tests. Three pieces of reinforcing steel bars were tested for each nominal diameter and average characteristic mechanical properties were calculated.

\section{Experimental Program}

This experiment was carried out in two steps, a dynamic collapse experiment and a static collapse experiment. During the dynamic collapse experiment, the middle column B1 was suddenly removed to study the dynamic response and internal force redistribution of the model frame under gravity 

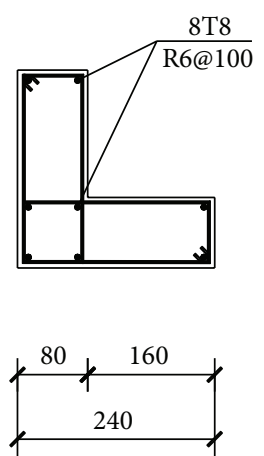

(a) Z1 column
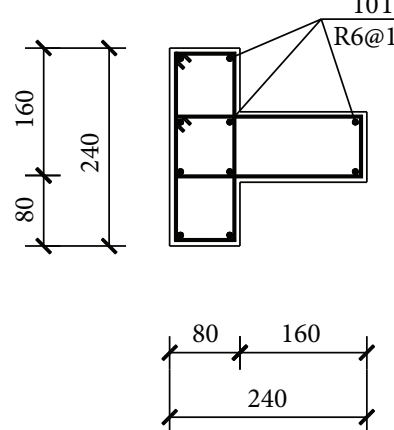

(b) Z2 column
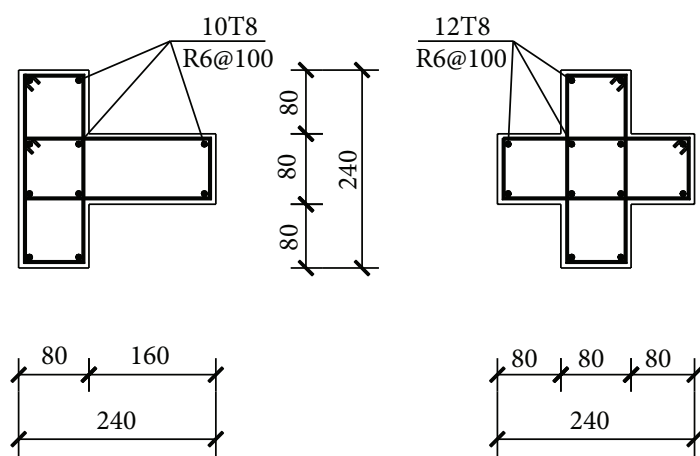

(c) Z3 column
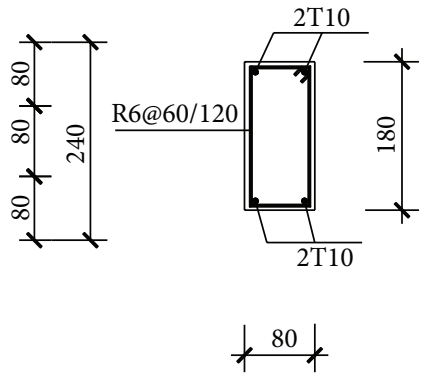

(d) Beam

FIGURE 2: Section dimension and reinforcement details of beam and columns. (Note: $\mathrm{R}$ and $\mathrm{T}$ stand for steel bars with nominal yield strengths of $300 \mathrm{MPa}$ and $400 \mathrm{MPa}$, resp.; the number following R or T represents the nominal diameter of a bar. @ stands for stirrup space. There is a decrease in spacing of stirrup by half of the near beam-column joint point according to Chinese seismic code.)

TABLE 1: Material properties of steel bars and concrete.

\begin{tabular}{lccccc}
\hline Bar type & $\begin{array}{c}\text { Yield strength } \\
(\mathrm{MPa})\end{array}$ & $\begin{array}{c}\text { Reinforcement } \\
\text { Ultimate tensile strength } \\
(\mathrm{MPa})\end{array}$ & $\begin{array}{c}\text { Elastic modulus } \\
(\mathrm{MPa})\end{array}$ & $\begin{array}{c}\text { Concrete } \\
\text { Ratio of elongation } \\
(\%)\end{array}$ & $\begin{array}{c}\text { Cubic compressive strength } \\
(\mathrm{MPa})\end{array}$ \\
\hline 300D6 & 417.0 & 541.4 & $2.12 \times 10^{5}$ & 30.5 & 42.3 \\
$400 \mathrm{D} 8$ & 454.1 & 640.3 & $2.65 \times 10^{5}$ & 28.5 & 29.1 \\
400D10 & 433.6 & 627.8 & $2.25 \times 10^{5}$ & 2 & \\
\hline
\end{tabular}

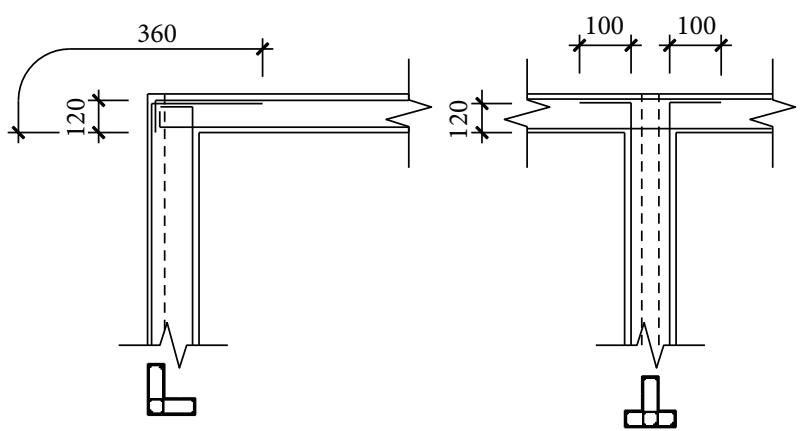

FIGURE 3: Reinforcement details of beam-column joints.

load. The experimental results of dynamic collapse test [17] show that the vertical displacement of the joint on the top of the failed column was only $0.176 \mathrm{~mm}$ and the dynamic response of the structure had no significant influence on the structure, which was still in the elastic stage, and collapse did not occur. Thus, a hydraulic jack placed on the top of the frame was used to apply a vertical load and conduct the static collapse test. The applied load is used to simulate the gravity load of the upper structure. The applied load was constantly increased until the damage of frame to study the resistance to progressive collapse, mechanism of collapse failure, and the final failure modes. The static collapse test was mainly introduced in this paper.

3.1. Loading Equipment and Protocol. As shown in Figure 4, the load in the dynamic collapse experiment was applied by

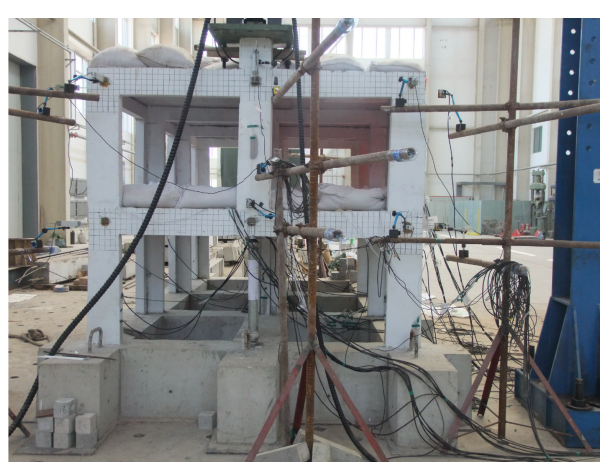

FIgURE 4: View of experimental model frame.

stacking sandbags uniformly on the slab. The load applied on the model frame was $2.8 \mathrm{kN} / \mathrm{m}^{2}$, which was the initial stress state of the frame. The static collapse test was conducted with a 100-ton hydraulic jack applying a vertical continuous load on the top of the frame. The loading device is schematically shown in Figure 5. The loading process was divided into two stages. Before the model frame yielded, the loading process was controlled by force. The load increment for each step was $10 \mathrm{kN}$ with a rate of $20 \mathrm{kN} / \mathrm{min}$. After the model frame yielded, a displacement-controlled manner was applied with a rate of $2 \mathrm{~mm} / \mathrm{min}$. In the beginning, the displacement increment for each step was $2 \mathrm{~mm}$ and then increased to $5 \mathrm{~mm}$ after the vertical displacement exceeding $38 \mathrm{~mm}$. At the final stage, the load was continuously applied until the 


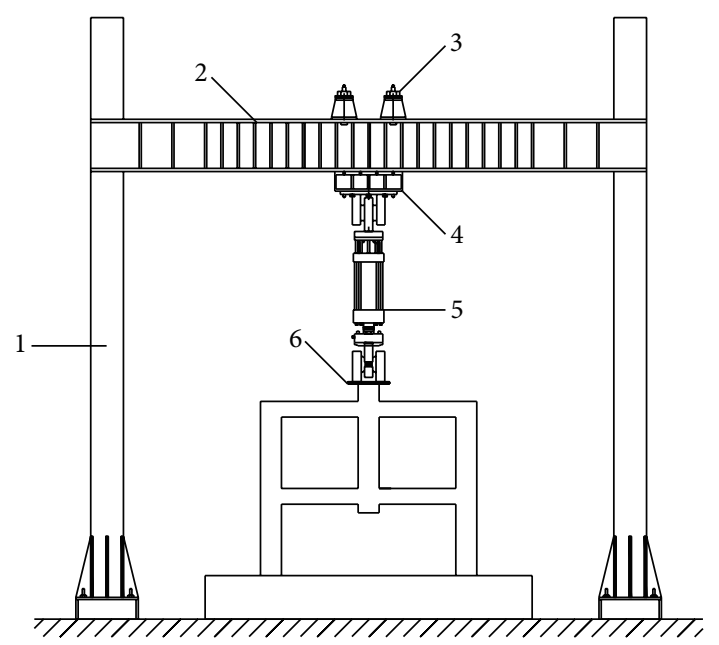

FIGURE 5: Schematic diagram of loading equipment. (Note: 1. column; 2 . load-carrying beam; 3 . girder; 4 . box girder; 5 . servohydraulic actuator; 6 . steel plate.)

end of test. After each loading step, the load was held for 612 minutes to observe and record experimental phenomena such as crack development and variations.

3.2. Test Setup and Instrumentation. Strain gauges and displacement transducers were set up in key locations of the model frame. The displacement transducers were placed to measure the vertical displacement of the joint on the top of the failed column and the horizontal displacement of the model frame. Concrete strain gauges were attached onto the surface of concrete to obtain the strain data of concrete at the middle and bottom of the ground floor columns. Steel bar strain gauges were affixed on steel bars at the ends and midspan of the beams connected to the failed column. The detailed positions of the displacement transducers and strain gauges attached onto steel bars and concrete are shown in Figure 6.

\section{Experimental Results}

4.1. Experimental Phenomena and Failure Modes. Under monotonic vertical concentrated load on the top of the frame, the test frame experienced large displacements and rotations at the ends of the beams before failure. The failure was characterized by the following sequence: (1) crushing and spalling of concrete at the top of beam ends near the failed column and at the bottom of beam ends far away from the failed column; (2) development of flexural and shear cracks at beam ends and beam-column joints (deepening and widening); and (3) destruction of beam-column joint with a major crack opening at the joint. When the vertical displacement of the joint reached $170 \mathrm{~mm}$ with a corresponding beam chord rotation of $0.142 \mathrm{rad}$, obtained by dividing the center column displacement by the centerline-to-centerline beam span of $1200 \mathrm{~mm}$, the top floor beam-column joints were heavily damaged and unable to provide enough anchorage for the longitudinal steel bars in beams. The frame entered an irreversible collapse process and the test was terminated. The pictures of the damaged model frame are shown in Figure 7. As shown in the figure, the beam-column joints at the top floor of the frame were seriously damaged, indicating that the joints of frame structures with specially shaped columns were the weak areas to resist progressive collapse. This is contrary to the design principles "strong column and weak beam, strong shearing and weak bend, stronger nodes." Moreover, the research results of Yi et al. [8] and Yu and Tan [11] show that the bearing capacities of the catenary action stage generally will increase and exceed that of flexural capacity of frame beam. However, the damage of beam-column joints limits the development of the catenary action when the joints damaged before the frame beam. Thus, these beamcolumn joints should be further enhanced in progressive collapse-resistant design to gain a better progressive collapse resistance.

4.2. Crack Patterns. Flexural cracks appeared in the frame beams near the middle column at both ground and top floor when testing commenced with vertical displacement of the joint. At a displacement of approximately $3.2 \mathrm{~mm}$, diagonal cracks appeared along the beams as well as at joints of the top floor and the flexural cracks bend slightly due to shear and twist of the beam. When the displacement of the joint reached $3.5 \mathrm{~mm}$, horizontal cracks appeared at the top of columns $\mathrm{A} 1$ and $\mathrm{C} 1$ in the top floor. It is seen that horizontal cracks appeared at the bottom of the top floor column B1 due to the twist of the beam. As the vertical displacement of the joint approached $19.5 \mathrm{~mm}$, shear cracks developed at the bottom halves of the ground floor columns. At approximately the same stage, the concrete located in the tensile zone experienced spalling. The concrete located in the compressive zone experienced crushing and spalling at the later stage of loading. Figure 8 shows a map of cracks at a vertical displacement of approximately $105 \mathrm{~mm}$. At this displacement, the maximum crack width was approximately $7 \mathrm{~mm}$. With the increase of displacement, crack width increased continuously and penetrated through the beam without new cracks appearing. It was noted that cracks on the bottom surface of slabs extended to the cracks at the ends of beams along the diagonal line between column B1 and columns A2, C2 during the loading process, as shown in Figure 9.

4.3. Load-Displacement Relationship of Failed Column. The main purpose of the testing was to observe the loaddisplacement response of the failed column. Figure 10 shows the relationship between the load applied by the hydraulic jack and the vertical displacement of the joint. With the gradual increase of the vertical displacement, the bearing capacity also increased rapidly. The applied load reached the maximum value of approximately $256 \mathrm{kN}$ at a vertical displacement of $65 \mathrm{~mm}$. The whole loading process can be divided into four stages.

As illustrated in Figure 10, the OA segment can be considered as the elastic stage, during which the relationship between the load and the vertical displacement of the joint is linear, without obvious destruction in the model frame. The 


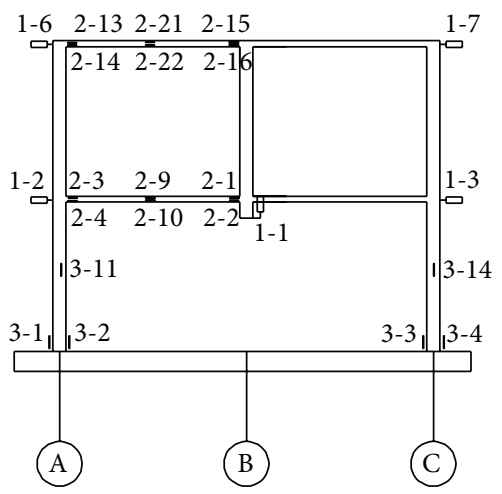

(a) Axis 1

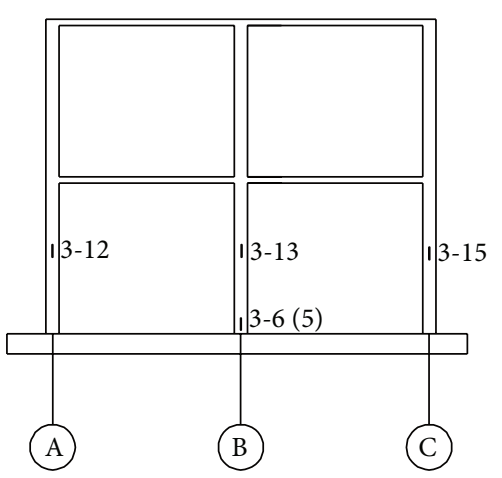

(b) Axis 2

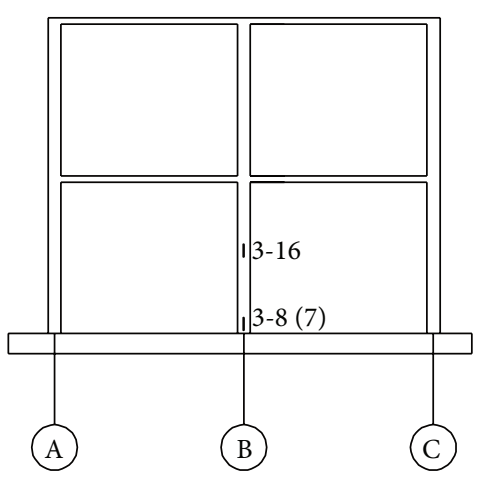

(c) Axis 3

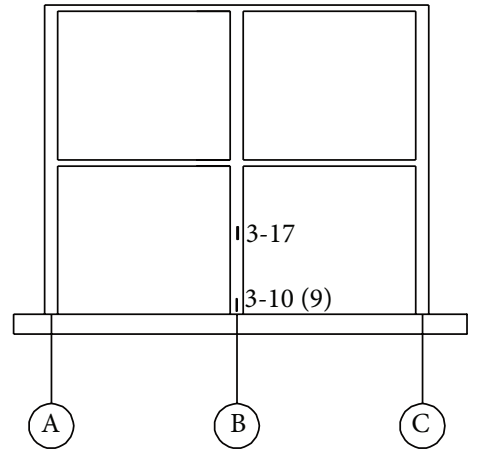

(d) Axis 4

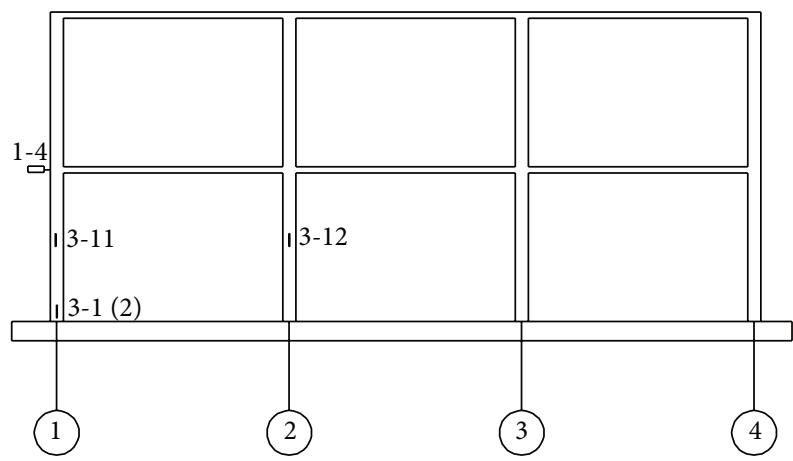

(e) Axis A

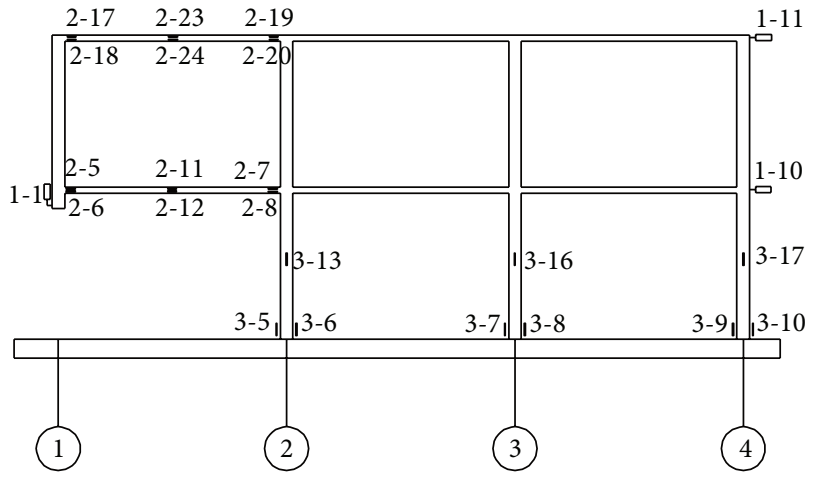

(f) Axis B

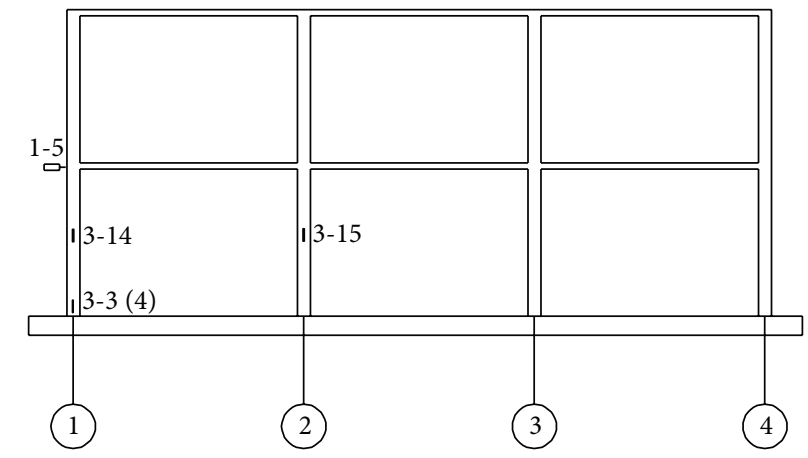

(g) Axis C

Figure 6: Details of testing setup and instrumentation. (Note: 1-1 to 1-11: displacement transducers; 2-1 to 2-24: steel strain gauges; 3-1 to 3-17: concrete strain gauges.)

$\mathrm{AB}$ segment is the elastoplastic or the start of the inelastic stage. The load is in a nonlinear relationship with the increase of displacement and the structural stiffness begins to decline at this stage. From the measured steel strains, it was observed that the longitudinal reinforcement at the ends of beams began to yield, indicating the formation of plastic hinges in the beams. And, most of the steel bars at the ends of beams had yielded at Point $\mathrm{B}$. The $\mathrm{BC}$ segment is the plastic hinge stage. Plastic hinges at the ends of beams were all formed and the structure gradually became a plastic stress system. Serious concrete crushing was observed from Point B and the concrete spalling appeared at the later period in this stage. The progressive collapse resistance of the test frame began to decrease after reaching its peak value of $256 \mathrm{kN}$. The CD segment is the catenary action stage. The flexural capacity of beams was almost lost at this stage. The tension cracks developed and penetrated through the compression zones, indicating the formation of the catenary mechanism in the beams. The measured strain in the upper steel bars changed to tension from compression, which indicates that the whole beam was in tension and the structure began to transfer load mainly by the steel bars. Because the beamcolumn joints at the top floor were unable to provide enough anchorage for the longitudinal steel bars in the beams, the bearing capacity of the structure at the catenary action stage decreased continuously with the increment of the vertical 


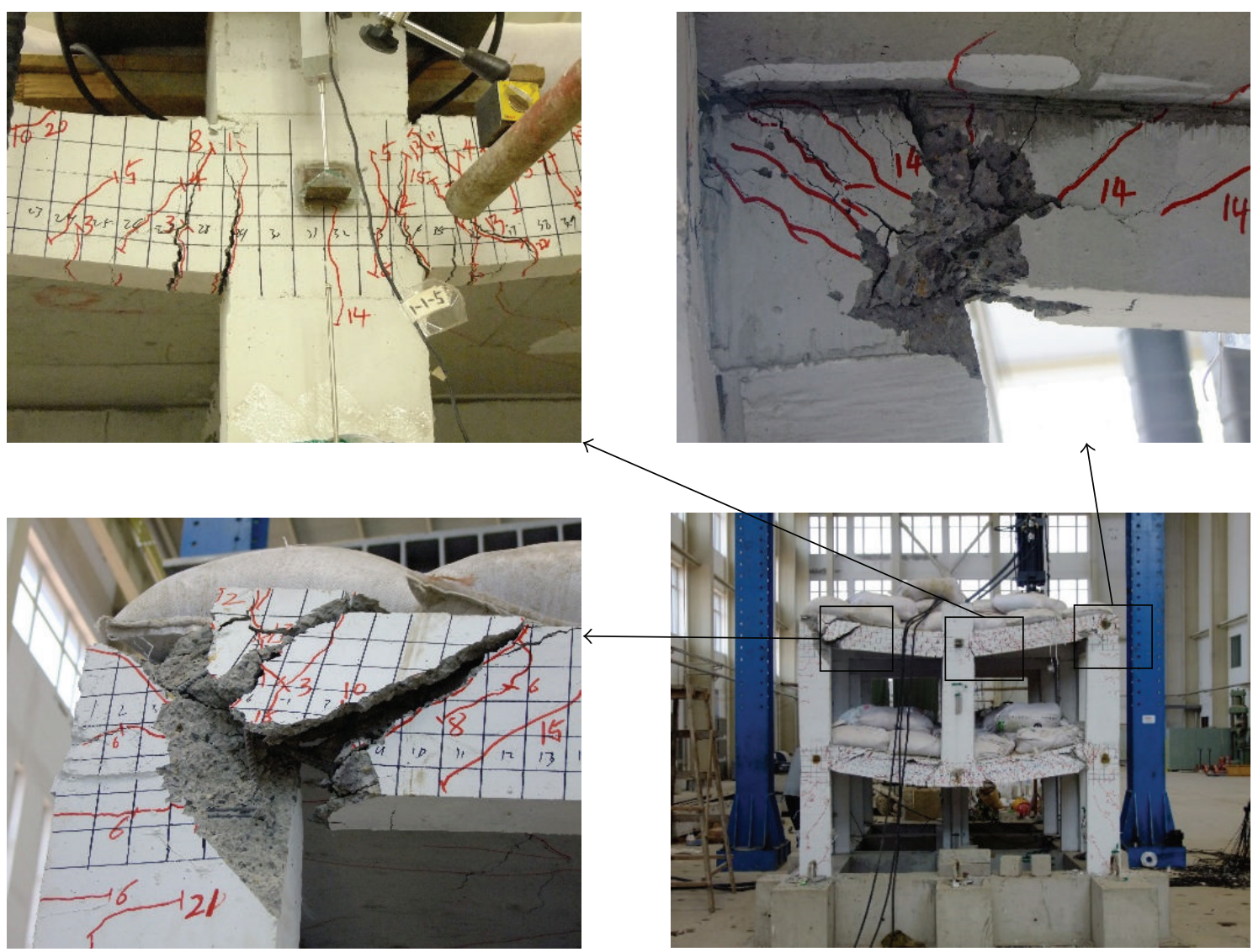

FIGURE 7: Failure modes of the test model.

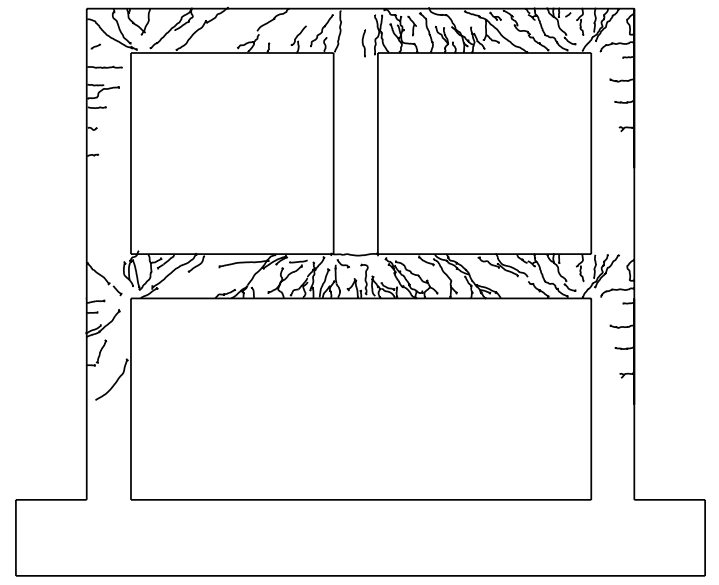

Figure 8: Crack pattern of model frame.

displacement. The structure entered an irreversible collapse process and the test was terminated since the serious damage of the beam-column joints at a vertical displacement of $170 \mathrm{~mm}$ (at Point D). The load transfer path was comparably more and the load variation was relatively stable without sudden drop of load during the catenary action stage due to the spatial action of the longitudinal frame beams and castin-place floor slabs. The frame beams and cast-in-place floors

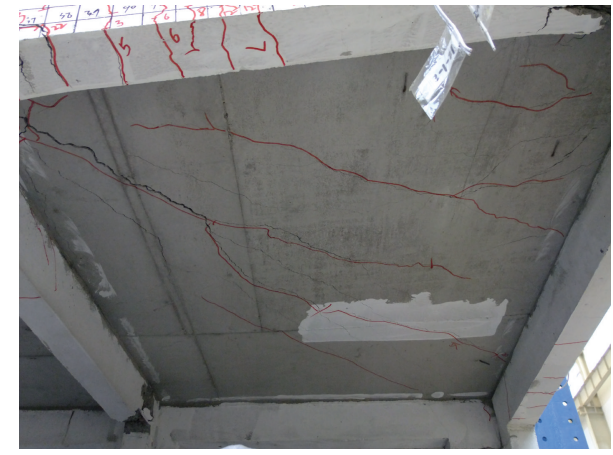

Figure 9: Crack on bottom surface of slab.

significantly improved the ductility of the structure, leading to plastic failure during structural collapse, which played an important role in the delay and inhibition of structural collapse.

4.4. Horizontal Displacement of Frame Column. The relationship of the horizontal displacement of the adjacent columns, both at the ground floor and at the top floor, and the vertical displacement of the joint is shown in Figure 11(a). The increase of horizontal displacement indicates that the measurement point is moving away from the failed column, 


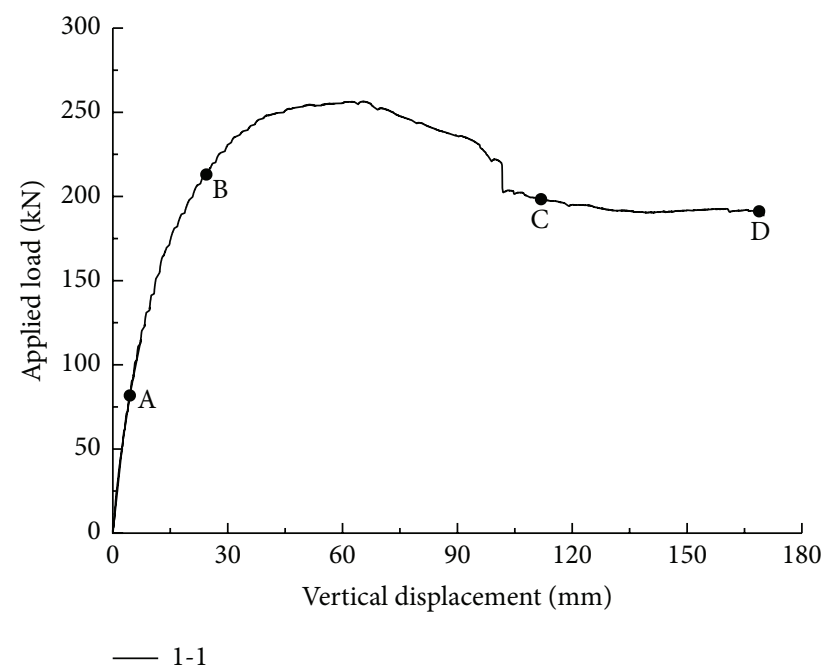

FIGURE 10: Applied load versus vertical displacement of the joint.

whereas the decrease means that it is moving towards the column. As exhibited in the figure, the adjacent columns moved outward during the initial loading stage under the influence of compressive arch action. The outward movement stopped after the vertical displacement exceeded about $65 \mathrm{~mm}$ with a maximum outward displacement of approximately $5 \mathrm{~mm}$. With the development of plastic hinge in the frame beam, the compressive arch action disappeared, and the adjacent frame columns began to move toward their initial position. When the vertical displacement of the joint was about $135 \mathrm{~mm}$, the adjacent frame columns moved back to their original position. As the vertical displacement increased, the adjacent frame columns tended to be pulled inward due to catenary action. The maximum inward displacement at the top of the adjacent frame columns was about $2 \mathrm{~mm}$ relative to the original position. During the whole experiment, the horizontal displacement of the top floor columns changed similarly to the ground floor columns, and the displacement of top floor columns was slightly higher after the frame entering the catenary action stage. When the vertical displacement exceeded $65 \mathrm{~mm}$, cracking of the concrete at the top floor beam-column joint led to a larger value measured by the displacement transducers at the measurement point 1-6.

Figure 11(b) depicts the variation of the horizontal displacement along the longitudinal direction of the frame in $B$ axis. At the early stage of the test, the columns far away from the failed column moved toward Axis 1. This was attributed to the fact that the side frames of Axis 4 were in tension under the combined action of the longitudinal frame beams and floor slabs during the time the failed column moved downward. The horizontal displacement of the top floor column was greater than that of the ground floor, and the displacement variation of the top floor frame was also more obvious. With the formation of plastic hinge and crush of concrete at the ends of B1-B2 beam and the floor slabs deactivated gradually since the development of cracks, the lateral force applied on the side frame declined, and the frame began to move outward (moving toward its initial position).

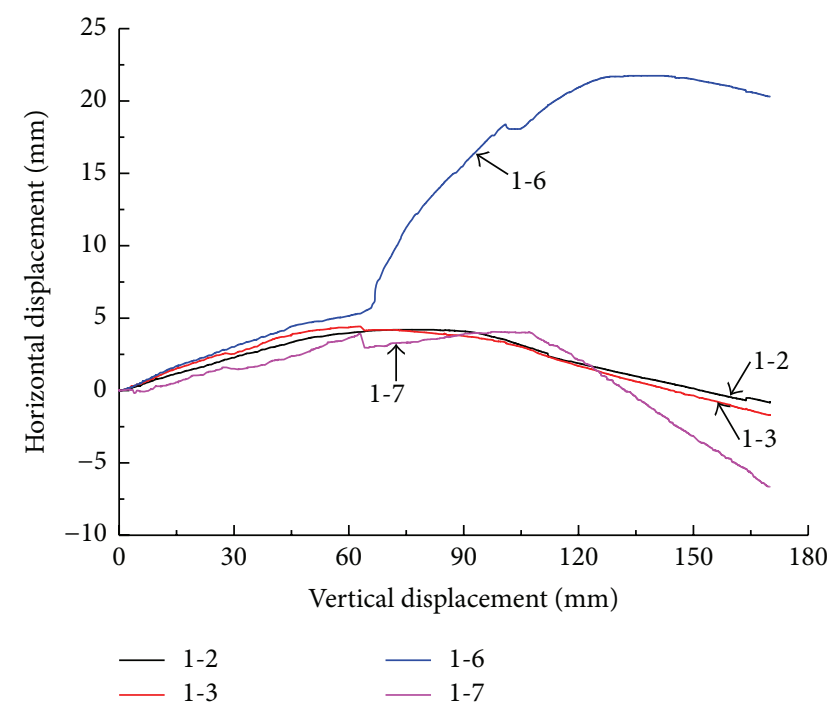

(a)

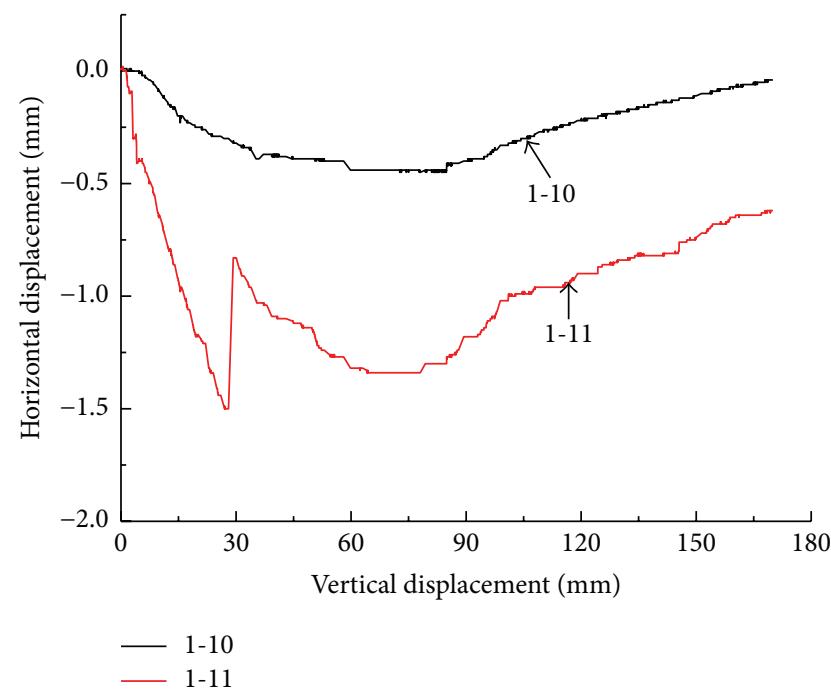

(b)

FIGURE 11: Relationship between the horizontal displacement and the vertical displacement of the joint.

During the test, the vertical displacement at the top of A4 column on the ground floor always changed around zero, indicating that the missing of B1 column had little influence on the corner column.

4.5. Strain of Steel Bars. The variation of the steel strain at the ends of A1-B1 beam as a function of the vertical displacement of the joint is shown in Figure 12. As depicted in the figure, the variation of the steel strains at the same cross sections at both the top and ground floors was similar. The steel strains in top floor beams were slightly greater than those in ground floor beams with a higher strain rate at corresponding sections. It is observed that most of the tensile reinforcement had yielded at the early stage of loading. The strain gauges on the tensile reinforcement fractured at a vertical displacement of about $30 \mathrm{~mm}$. It is noted that the steel strain in measurement 


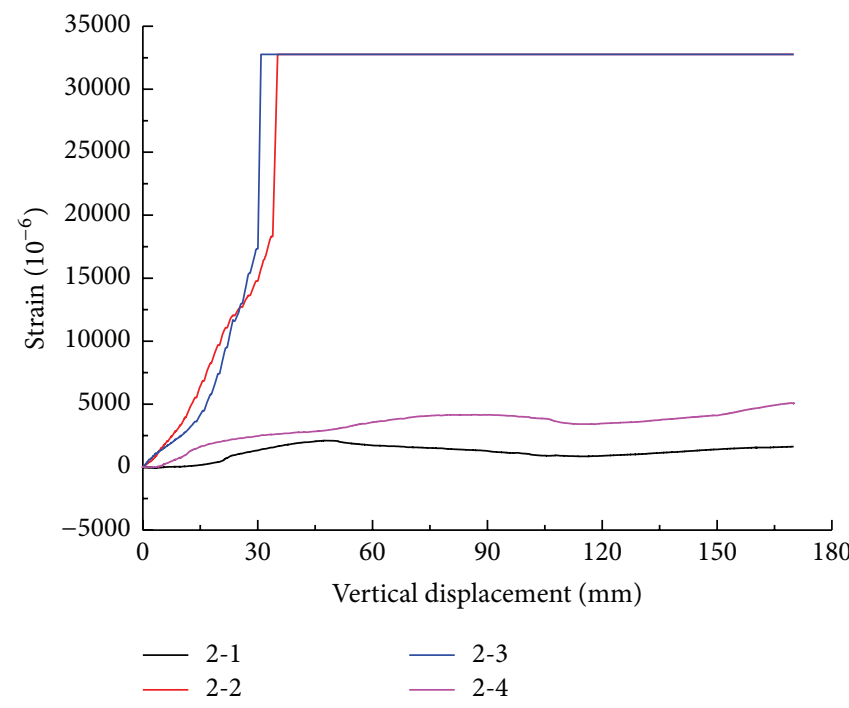

(a) Ground floor

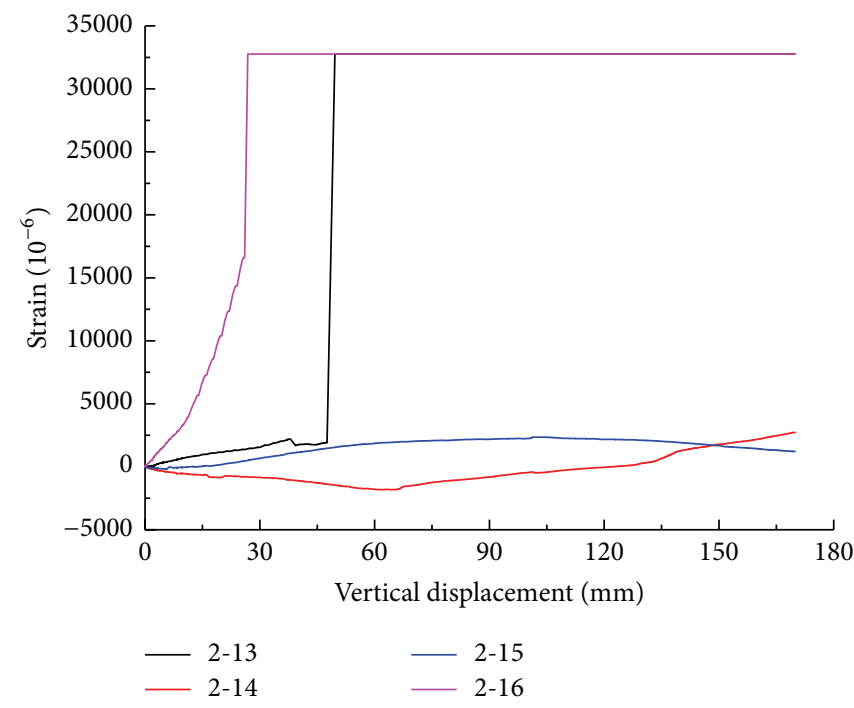

(b) Top floor

FIGURE 12: Strain response at the ends of beam A1-B1.

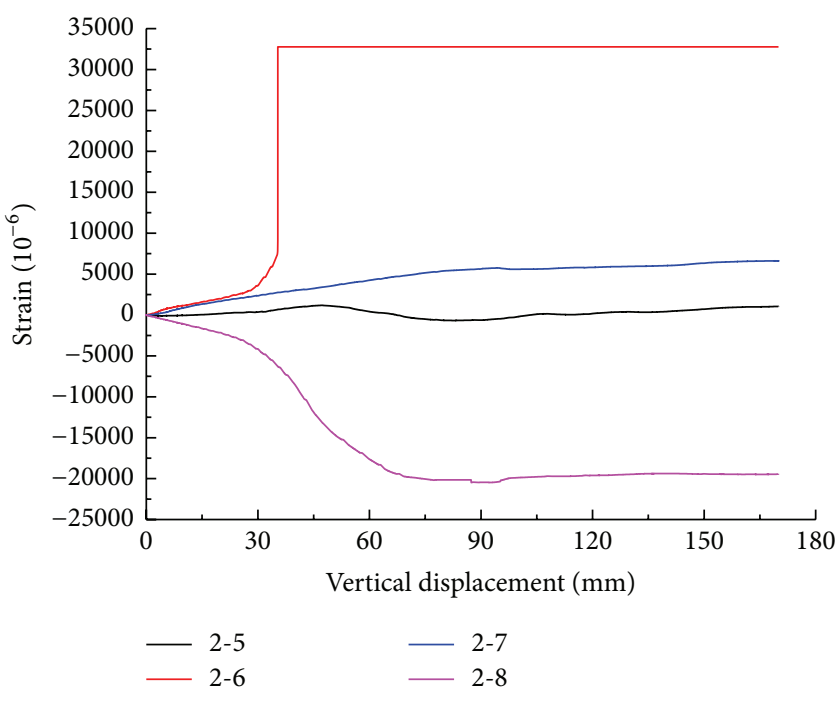

(a) Ground floor

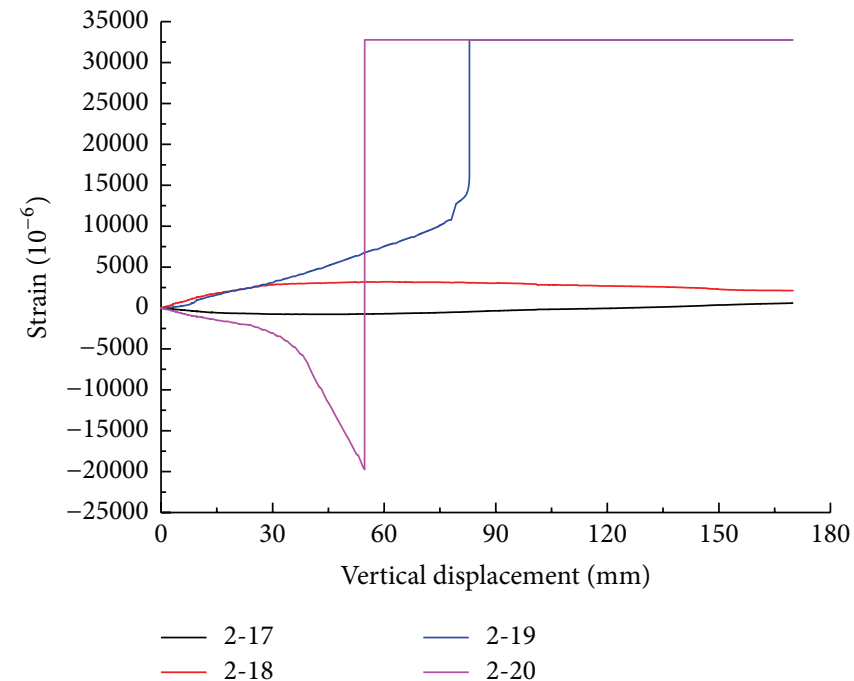

(b) Top floor

FIGURE 13: Strain response at the ends of beam B1-B2.

point 2-14 changed from compression to tension while the vertical displacement exceeded about $135 \mathrm{~mm}$, which suggests the gradual forming of catenary action. Figure 13 shows the relationship of the steel strains at the ends of the longitudinal beam B1-B2 versus the vertical displacement of the joint. Steel bars at the bottom of the beam ends far away from the failed column were always in a compressive state indicating that the longitudinal frame beam connected to the failed column was in a cantilever state and the catenary action was unable to activate. The strain of this reinforcement monotonically increased and rapidly exceeded yielding strains with the crushing and spalling of concrete.

The relationship between the steel strains at the midspan of A1-B1 and B1-B2 beam and the vertical displacement of the joint are displayed in Figure 14. At the early stage of loading, the compressive strain in the top steel bars at the midspan of the ground floor beam increased slowly indicating the formation of compressive arch action. The compressive strain decreased to zero at the vertical displacement of about $120 \mathrm{~mm}$. Then, the frame beams changed to tension from the previous compression state, and the frame entered the catenary action stage. Meanwhile, the midspan section of the top floor beam was in tension all the time, indicating the restriction effect of frame beam on the columns. The horizontal displacement of the top floor columns should be two times that of the ground floor columns when the frame columns moved laterally with the column foot as the rotation center. However, the displacements of both the top floor and 


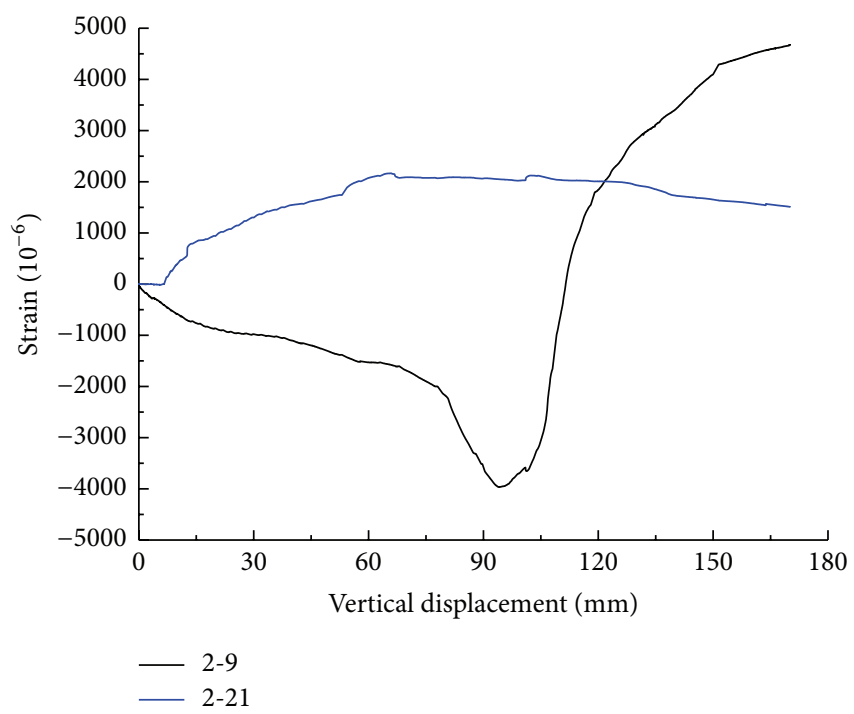

(a) A1-B1 beam

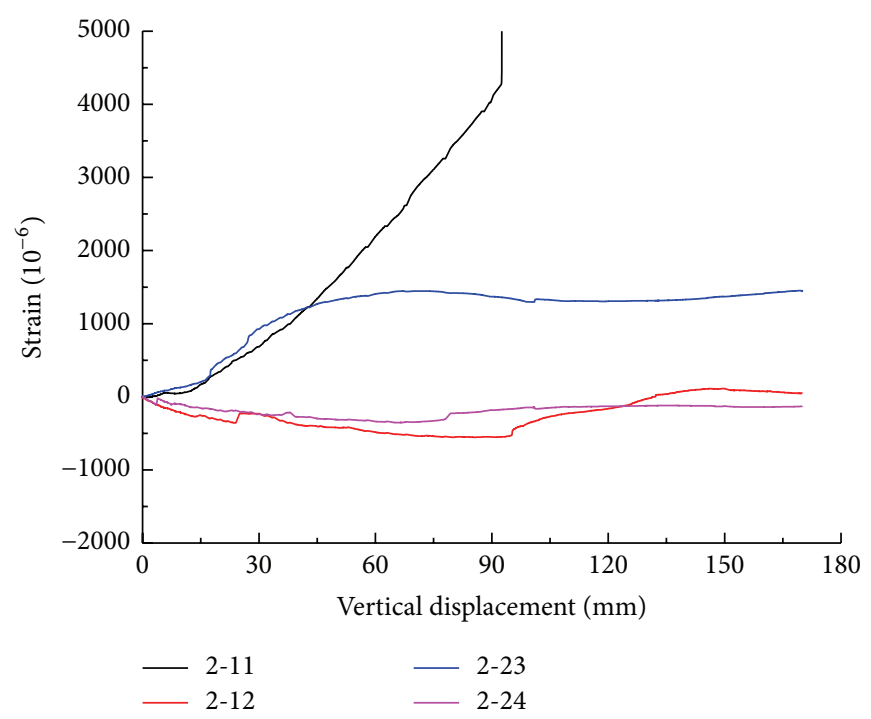

(b) B1-B2 beam

FIGURE 14: Strain response at the midspan of beam.

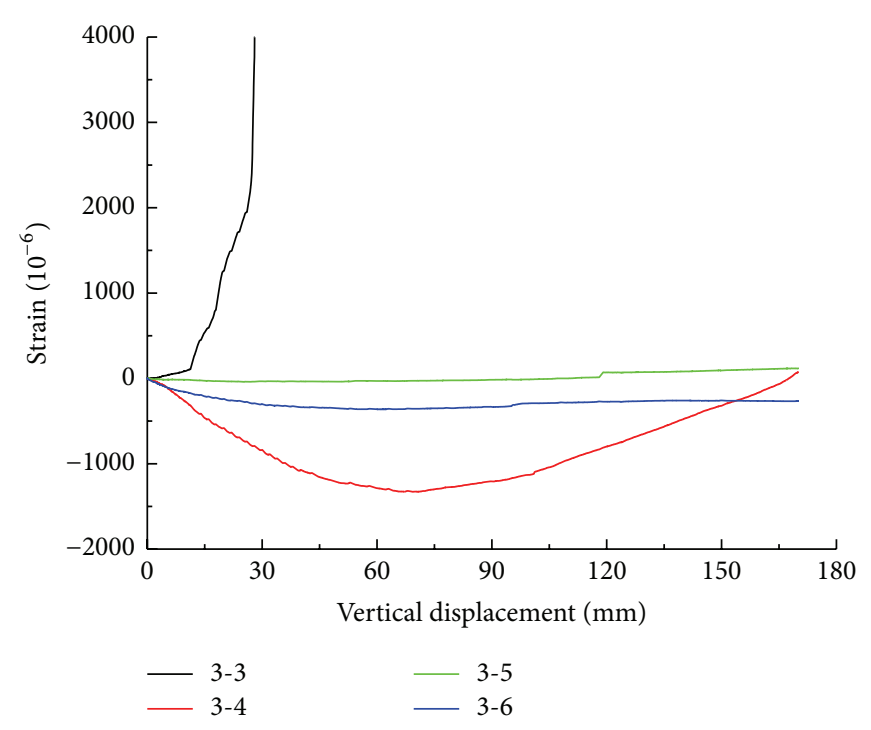

(a) Columns $\mathrm{Cl}$ and $\mathrm{B} 2$

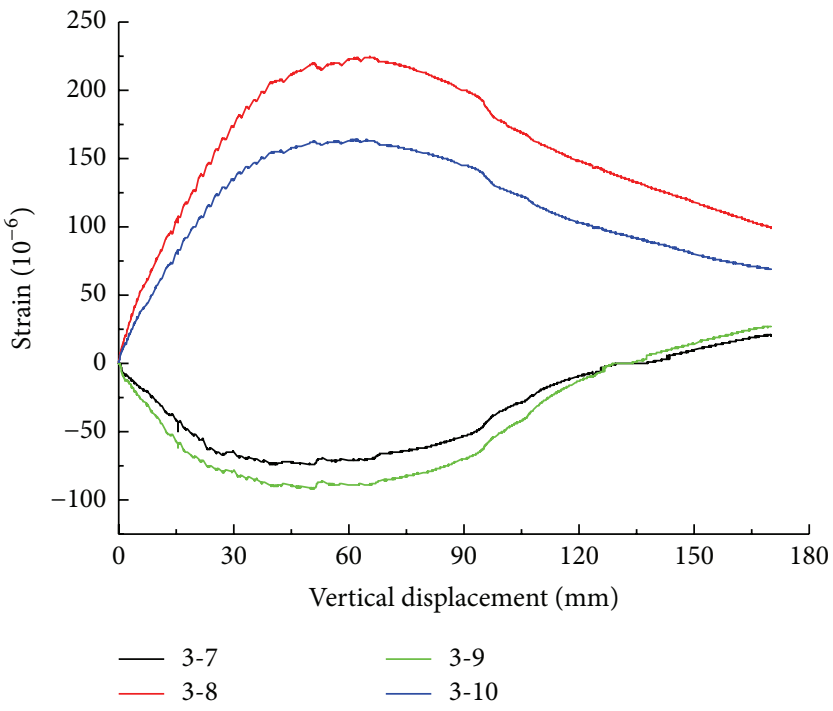

(b) Columns B3 and B4

FIGURE 15: Concrete strain response at the bottom of frame column.

ground floor columns were close to each other under the spatial action of the superstructure, as shown in Figure 11(a), which suggested that the top floor beams limited the outward movement of the columns connected to it, leading to the tensile state of the whole beams. With the lateral displacement of the ground floor columns decreasing, the tensile strain in the top steel bars of the top floor beam also decreased. The frame beam B1-B2 was in a cantilever state and its loadcarrying condition was relatively simple. The tensile strain in the top steel bars at the midspan increased slowly whereas the strain of the bottom steel bars remained small and tended to tension in the later stage.

4.6. Concrete Surface Strain. The variation of surface strain in concrete at the bottom of the ground floor columns as a function of the vertical displacement of the joint is shown in Figure 15. The strain gauges were attached to the surface of concrete on two sides of the column feet along the bending direction, with a distance of $20 \mathrm{~mm}$ to the column foot. As shown in Figure 15(a), the compressive strains on the outside surface (the surface away from the failed column) of columns adjacent to the failed column reached their minimum values and began to increase after the vertical displacement reached approximately $65 \mathrm{~mm}$. This is consistent with the trend observed for the horizontal displacements of ground floor columns previously, displayed in Figure 11(a), and confirms the existence of compressive arch action again. Because the strain gauge on the tensile side was located across a crack, the measured tensile strain in concrete increased rapidly and the strain gauges fractured while the displacement exceeded 


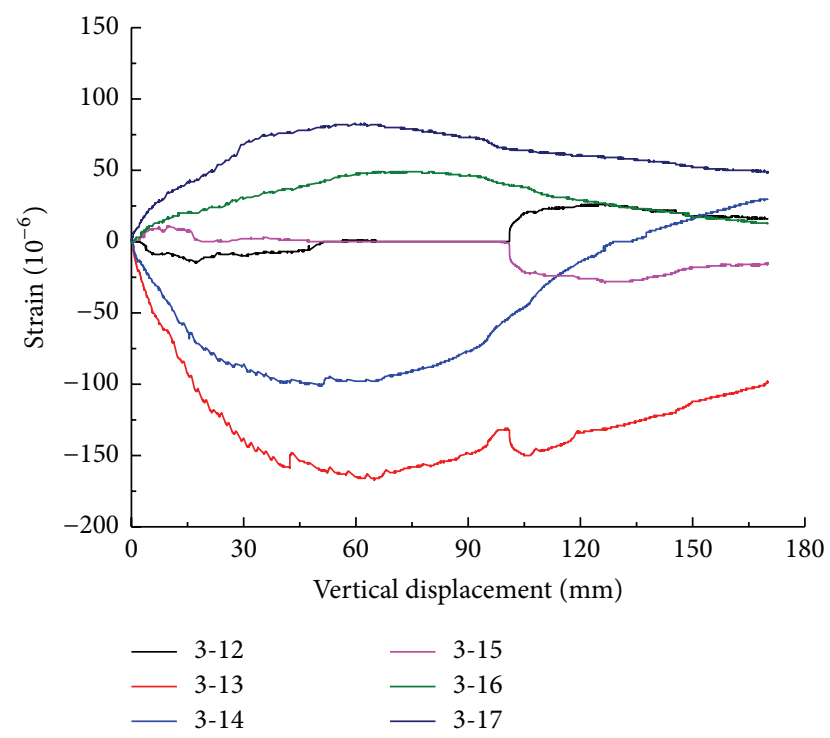

FIGURE 16: Concrete strain response at the middle of frame column.

$30 \mathrm{~mm}$. The concrete strain at the bottom of column far away from the failed column, as shown in Figure 15(b), changed gradually with tensile strain on the outside surface (the surface away from the failed column) and the compressive strain on the inside surface (the surface toward the failed column) under the combined action of moment and axial force. This was consistent with the variation of the frame's overall horizontal displacement along the long axis direction.

As illustrated in Figure 16, the compressive strain of concrete at the middle of $\mathrm{Cl}$ column, which was next to the failed column and in symmetry with the Al column, along with the B2 column, reached its minimum value and began to increase gradually at a displacement of approximately $65 \mathrm{~mm}$. This was because the internal force redistribution transferred the load carried by the failed column to the adjacent columns and increased the compressive stress of concrete. At the same time, the strains of other columns were in tension or approximate to zero with little variation due to the overall effect of the frame. The above results proved that, after the failure of the middle column at the ground floor, the load previously carried by the failed column was mainly transmitted to the frame columns adjacent to it; in contrast, the frame columns far away from the failed column share little. The internal force redistribution of the frame was primarily concentrated within the substructure adjacent to the failed column, with little influence on other components further away.

\section{Finite Element Analysis}

5.1. Finite Element Model. The OpenSees [18] platform was used in the simulations presented in this paper. The finite element model completely replicated the test model, in which the material properties and dimensions of the model were identical to the test model. The frame beam and

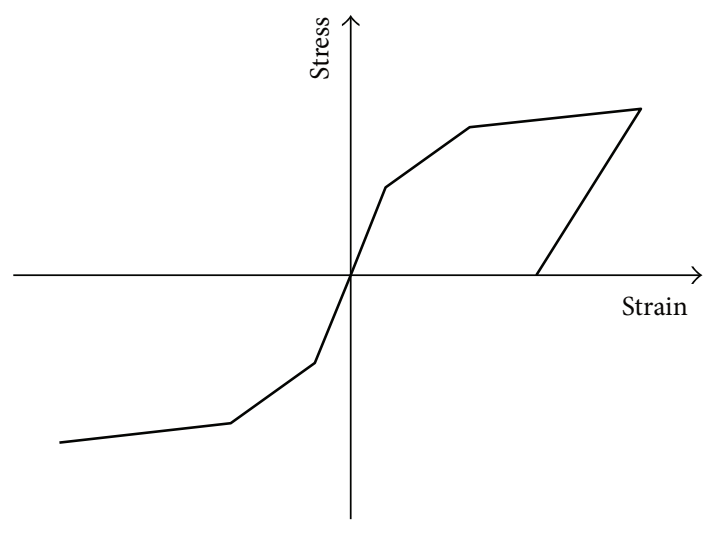

FIGURE 17: Stress-strain relationship of steel.

column components were simulated using the Force-Based Beam-Column Element, which was based on the iterative force-based formulation. A variety of numerical integration options can be used in the element state determination and encompass both distributed plasticity and plastic hinge integration. The resistance and tangent stiffness matrix of the whole element are integrated along the element length in accordance with Gauss-Lobatto integration on the basis of determining the resistance and stiffness matrix on the control section. The control section of the element was modeled by fiber element and the material properties of concrete and steel bars were, respectively, assigned to fibers. The finite element model was set up by beam elements with T-shaped or Lshaped sections, in which slabs were the flange of the frame beam, to consider the enhancement of slabs on beams. As shown in Figure 17, the steel reinforcing bars were modeled using the "Hysteretic Material" which allows the definition of trilinear behavior. The first branch was used to define the elastic response of the material, the second accounts for the hardening stage, while the final branch was specified with a negative slope up to bar rupture. The material used to define the concrete is the "Concrete02 Material," as shown in Figure 18, which utilizes the well-known Kent-Park model expanded by Scott et al. [19] in compression and linear elastic behavior in tension up to tension cracking followed by linear softening. There were two kinds of concrete: the core concrete (Confined Concrete) confined by stirrup and the cover concrete (Unconfined Concrete).

5.2. Comparison of Test and Analytical Results. The analytical results are compared with the experimental results in Figure 19. As can be seen from the figure, the calculated results are in good agreement with the experimental results in the initial stiffness and the whole bearing capacity. In general, the finite element model is accurate enough to conduct the progressive collapse analysis of RC frame structure with specially shaped columns, which can be used for further analysis in other scenarios such as frames of high rise buildings or a multibay frame. 


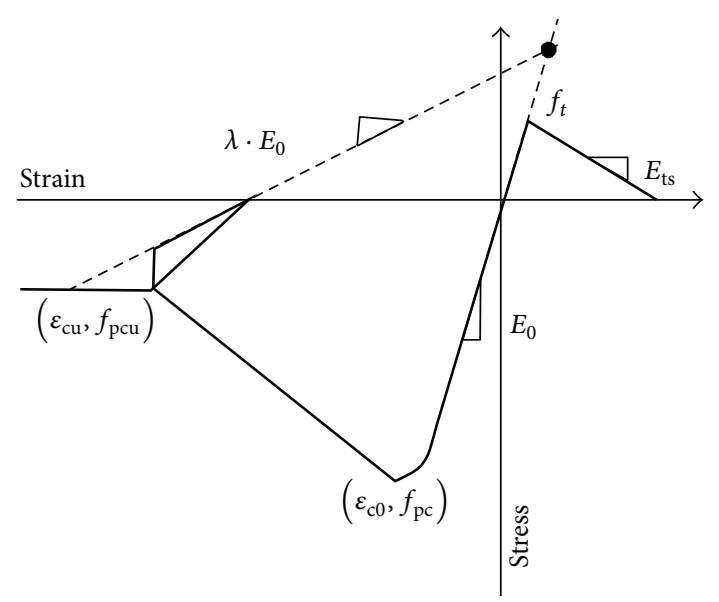

FIGURE 18: Stress-strain relationship of concrete.

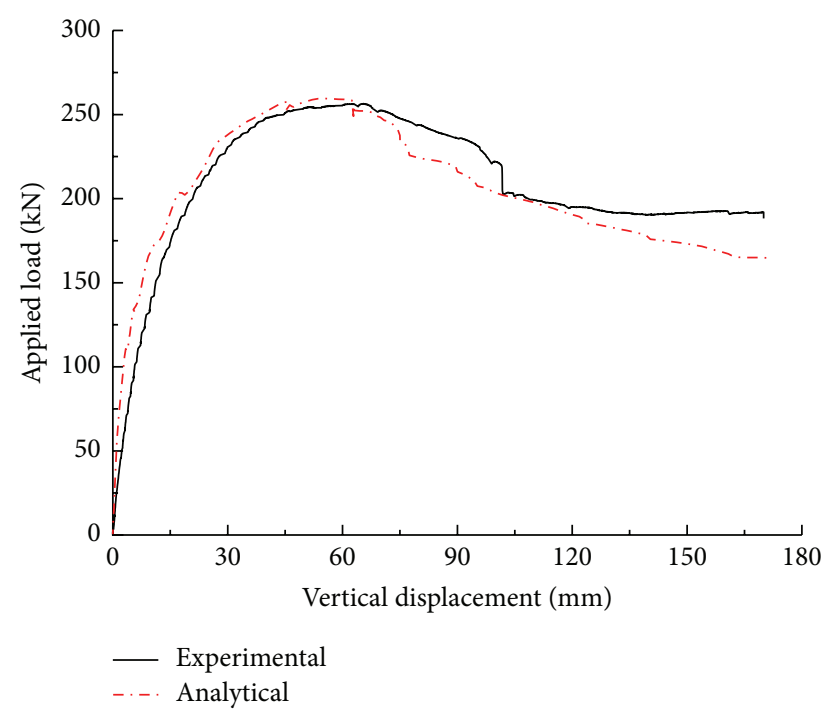

Figure 19: Applied load versus vertical displacement of the joint.

\section{Discussion of Load Resisting Mechanisms}

Figure 20 shows the transforming process of the load resisting mechanisms during the collapse of the frame with specially shaped columns. The transforming process can be summarized as a three-stage process: (1) a compressive arch action stage, in which compressive axial forces developed in the beams due to horizontal restraint at the beam ends, providing additional stiffness and load-carrying capacity; (2) a plastic hinge stage, in which flexural bending caused reinforcing bars to yield in tension and concrete to soften and crush in compression, causing a reduction in load-carrying capacity; and (3) a catenary action stage, in which tensile axial forces were mobilized in the beams as the deflection of the failed column exceeded the depth of the beam.

As shown in Figure 20, the structural deformation was small and minor cracks developed in the beams during the early stage of loading. These cracks, however, did not cause a significant decrease in the overall stiffness of the beams.

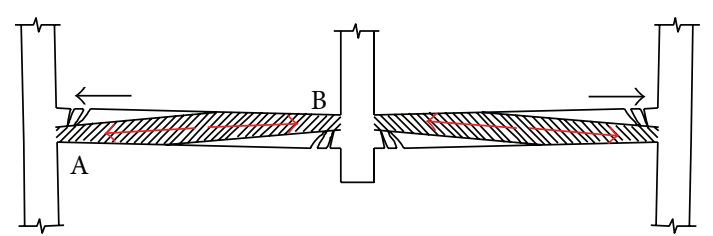

(a) Compressive arch action stage

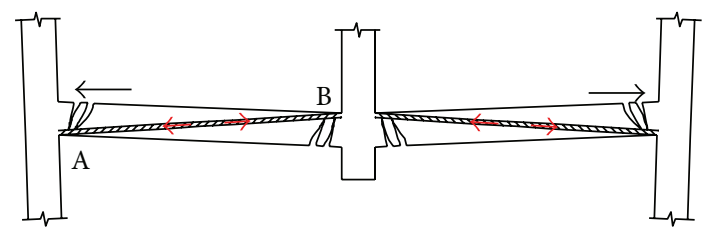

(b) Plastic hinge stage

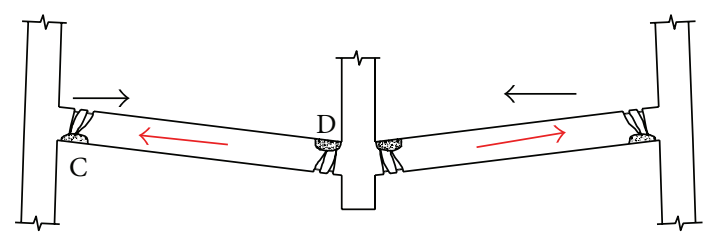

(c) Catenary action stage

Figure 20: Load transfer mechanisms of frame with specially shaped columns.

At this stage, the beam ends near the failed column were in compression at the top and in tension at the bottom, while the beam ends far away from the failed column were in tension at the top and in compression at the bottom. A compressive arch formed within the beam due to the restraint provided by the end columns. The presence of beam axial compression enhances the flexural strength of a beam via standard flexural-axial interaction and, in turn, its resistance to progressive collapse. With the increase of the vertical displacement, the depth of the compression zone at the beam end decreased, and the height of the compression zone in the fame beam also decreased. The frame beam entered the plastic hinge stage. Pronounced degradation of the beam stiffness was observed at this stage because of yielding of the reinforcing bars. After reaching the initial peak load, the load began to drop with increasing vertical displacement. According to the study of Yu and Tan [11] and Bao et al. [20], the load will level off and start to increase again when the vertical displacement of the failed column exceeds the depth of the beam, and catenary forces will develop in the beams along with full-depth cracks. The development of catenary force was evidenced by tensile strains in reinforcing bars at midspan of beams. The catenary force is the total tension force in the cross section provided by the steel, which needs a good anchorage at the beam ends. However, anchorage for longitudinal steel bars depended mainly on the bond effect between the reinforcement and concrete. Specially shaped columns, whose width of column flanges and beams is imposed to be identical, are different from ordinary columns. Their limbs thickness is small, steel bars are dense, and the stress distribution is more complicated, leading to less bond strength of the steel bars and reinforced concrete in the 
joints region. Moreover, the joints damaged before the frame beam during the test, which further weakened the bond anchorage of longitudinal steel bars. These factors lead to lack of anchorage for reinforcing bars at beam ends, which directly affected the development of the catenary forces. The bearing capacity of the structure at the catenary action stage decreased continuously rather than increasing. The frame failed due to the damage of joints with the failure load $(191.6 \mathrm{kN})$ being $75 \%$ of the initial peak load $(256.2 \mathrm{kN})$. That is, the ultimate bearing capacity of the frame with specially shaped columns was dominated by the flexural capacity of the beam while that of the frame with rectangular columns was dominated by the development of catenary action. For example, research results of Yu and Tan [11] show that the bearing capacities of the catenary action stage were $165 \%$ and $176 \%$ of flexural capacity with considering the presence of compressive arch action for specimens S1 and S2, respectively. This is a significant difference between the frame with specially shaped columns and the frame with rectangular columns.

\section{Conclusion}

Based on the observations and findings from the experimental study described in this paper, the progressive collapse performance and failure mechanism of frame with specially shaped columns were investigated, with the following conclusions obtained:

(1) The frame finally failed due to the damage of the top floor beam-column joints. The damaged beamcolumn joints could not provide enough anchorage for longitudinal steel bars at the beam ends, which directly affected the development of the catenary forces. The beam-column joints were proved to be a weak area of the structure to resist progressive collapse and will require further enhancements during the design stage.

(2) The collapse process of RC frame with specially shaped columns after one middle column removal experiences four distinct stages: elastic stage, elastoplastic stage, plastic hinge stage, and catenary action stage. Different from RC frame with rectangular columns, the redistribution of internal force for RC frame with specially shaped columns was mainly realized via the beam resisting mechanism and the compressive arch action in beams played an important role to improve the collapse-resistant capacity.

(3) The redistribution of the load carried by the failed column occurred during the column failure. During the load redistribution, the load mainly transferred toward the adjacent columns, while little load was sustained by the columns further away. The redistribution of internal force in the frame was mainly concentrated in the components around the failed column, with little influence on the other components.
(4) There was no sudden drop of load during the loading processing. The spatial connection action of the frame beams and cast-in-place slabs significantly increased the ductility of the structure and led to the plasticity failure of the structure during collapse. This could play an important role in the delay and inhibition of the structure collapse.

(5) Progressive collapse performance of the reinforced concrete frame structures can be well predicted using the finite element model proposed in this paper. The finite element analysis method can be used for further analysis in other scenarios such as frames of high rise buildings or a multibay frame.

\section{Conflict of Interests}

The authors declare that there is no conflict of interests regarding the publication of this paper.

\section{Acknowledgments}

The work presented in this paper was funded by the National Natural Science Foundation of China (no. 51178304) and the Specialized Research Fund for the Doctoral Program of Higher Education of China (no. 20120032120055), which are gratefully acknowledged.

\section{References}

[1] ASCE, Minimum Design Loads for Buildings and Other Structures, American Society of Civil Engineers, Reston, Va, USA, 2006.

[2] P. Kotsovinos and A. Usmani, "The World Trade Center 9/11 disaster and progressive collapse of tall buildings," Fire Technology, vol. 49, no. 3, pp. 741-765, 2013.

[3] GSA, Progressive Collapse Analysis and Design Guidelines for New Federal Office Buildings and Major Modernization Projects, US General Service Administration, Washington, DC, USA, 2003.

[4] European Committee for Standardization, EN 1991-1-7:2006, Eurocode 1: Actions on Structures. Part 1-7: General ActionsAccidental Actions, European Committee for Standardization, Brussels, Belgium, 2006.

[5] Office of the Deputy Prime Minister, BS 5950-1. The Building Regulations 2000: Part-A: Schedule 1: A3, Disproportionate Collapse, Office of the Deputy Prime Minister, London, UK, 2004.

[6] M. Sasani and J. Kropelnicki, "Progressive collapse analysis of an RC structure," The Structural Design of Tall and Special Buildings, vol. 17, no. 4, pp. 757-771, 2008.

[7] M. Sasani, M. Bazan, and S. Sagiroglu, "Experimental and analytical progressive collapse evaluation of actual reinforced concrete structure," ACI Structural Journal, vol. 104, no. 6, pp. 731-739, 2007.

[8] W.-J. Yi, Q.-F. He, Y. Xiao, and S. K. Kunnath, "Experimental study on progressive collapse-resistant behavior of reinforced concrete frame structures," ACI Structural Journal, vol. 105, no. 4, pp. 433-439, 2008. 
[9] J. Kim and J. Yu, "Analysis of reinforced concrete frames subjected to column loss," Magazine of Concrete Research, vol. 64, no. 1, pp. 21-33, 2012.

[10] Y. Su, Y. Tian, and X. Song, "Progressive collapse resistance of axially-restrained frame beams," ACI Structural Journal, vol. 106, no. 5, pp. 600-607, 2009.

[11] J. Yu and K.-H. Tan, "Experimental and numerical investigation on progressive collapse resistance of reinforced concrete beam column sub-assemblages," Engineering Structures, vol. 55, pp. 90-106, 2013.

[12] S. L. Yap and B. Li, "Experimental investigation of reinforced concrete exterior beam-column subassemblages for progressive collapse," ACI Structural Journal, vol. 108, no. 5, pp. 542-552, 2011.

[13] T.-C. Wang and X.-H. Zhang, "Frame property of unequal storey height with specially shaped columns under cyclic loading," Journal of Central South University of Technology, vol. 17, no. 6, pp. 1364-1369, 2010.

[14] T. Wang, X. Liu, and H. Zhao, "Experimental study of the seismic performance of L-shaped columns with $500 \mathrm{MPa}$ steel bars," The Scientific World Journal, vol. 2014, Article ID 105826, 11 pages, 2014.

[15] GB 50010-2010. Code for Design of Concrete Structures, China Architecture \& Building Press, Beijing, China, 2010, (Chinese).

[16] JGJ, “Technical specification for concrete structures with specially shaped columns," JGJ 149-2006, China Architecture \& Building Press, Beijing, China, 2006 (Chinese).

[17] T. Wang, Q. Chen, H. Zhao, and L. Zhang, "Investigation on dynamic effects of frame with specially shaped columns subjected to column failure," Journal of Vibroengineering, vol. 17, no. 5, pp. 2455-2470, 2015.

[18] F. McKenna, G. L. Fenves, and M. H. Scott, Open System for Earthquake Engineering Simulation, University of California, Berkeley, Calif, USA, 2000.

[19] B. D. Scott, R. Park, and M. Priestley, "Stress-strain behavior of concrete confined by overlapping hoops at low and high strain rates," ACI Journal Proceedings, vol. 79, no. 1, pp. 13-27, 1982.

[20] Y. Bao, H. S. Lew, and S. K. Kunnath, "Modeling of reinforced concrete assemblies under column-removal scenario," Journal of Structural Engineering, vol. 140, no. 1, Article ID 04013026, 2014. 


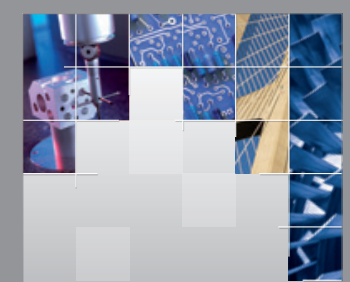

\section{Enfincering}
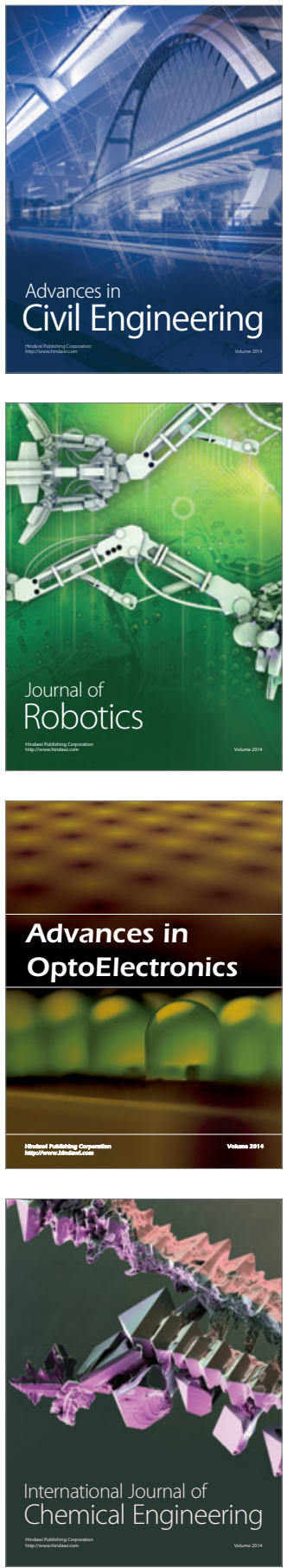

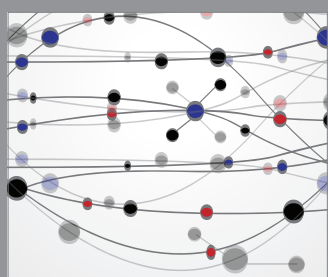

The Scientific World Journal

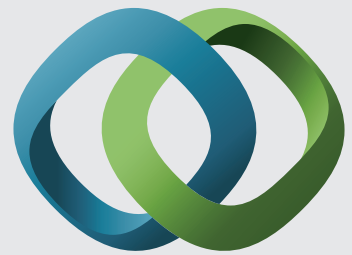

\section{Hindawi}

Submit your manuscripts at

http://www.hindawi.com
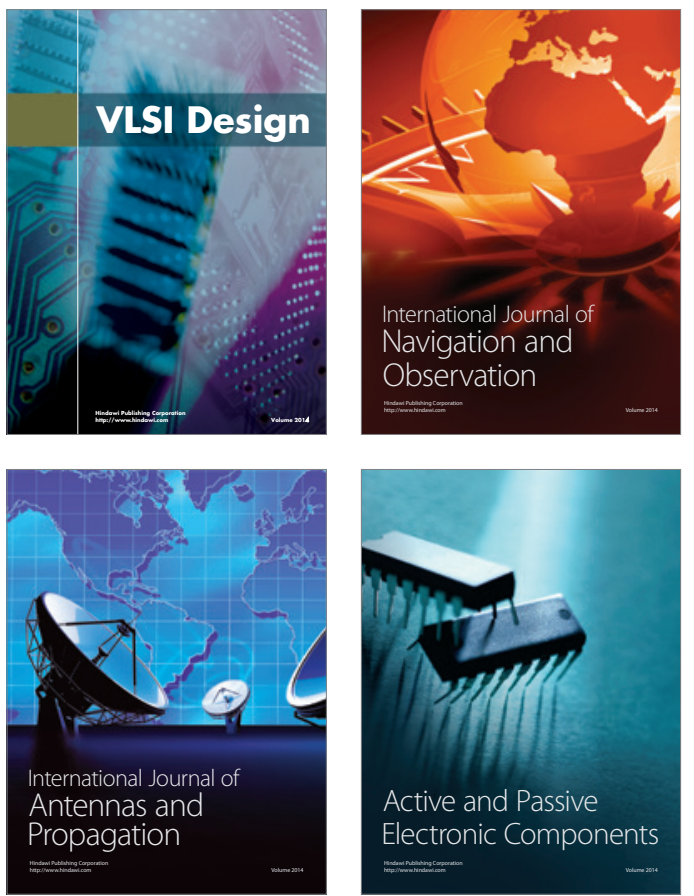
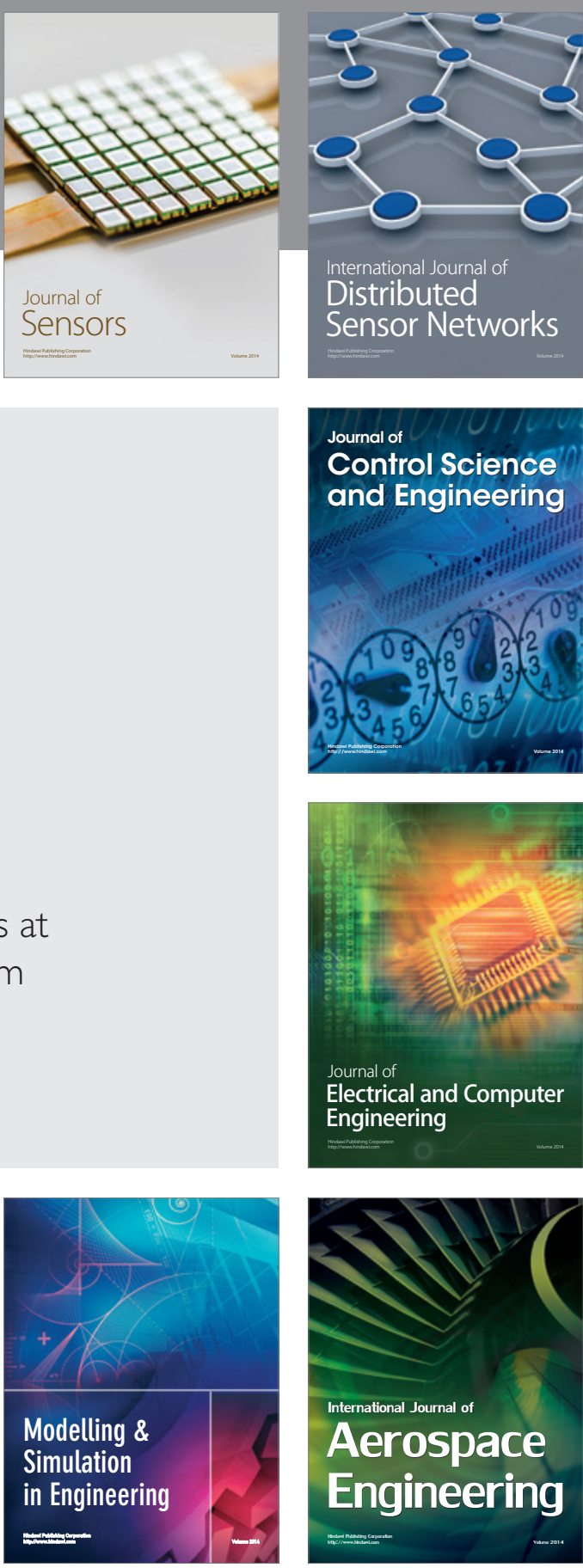

International Journal of

Distributed

Sensor Networks

Journal of

Control Science

and Engineering
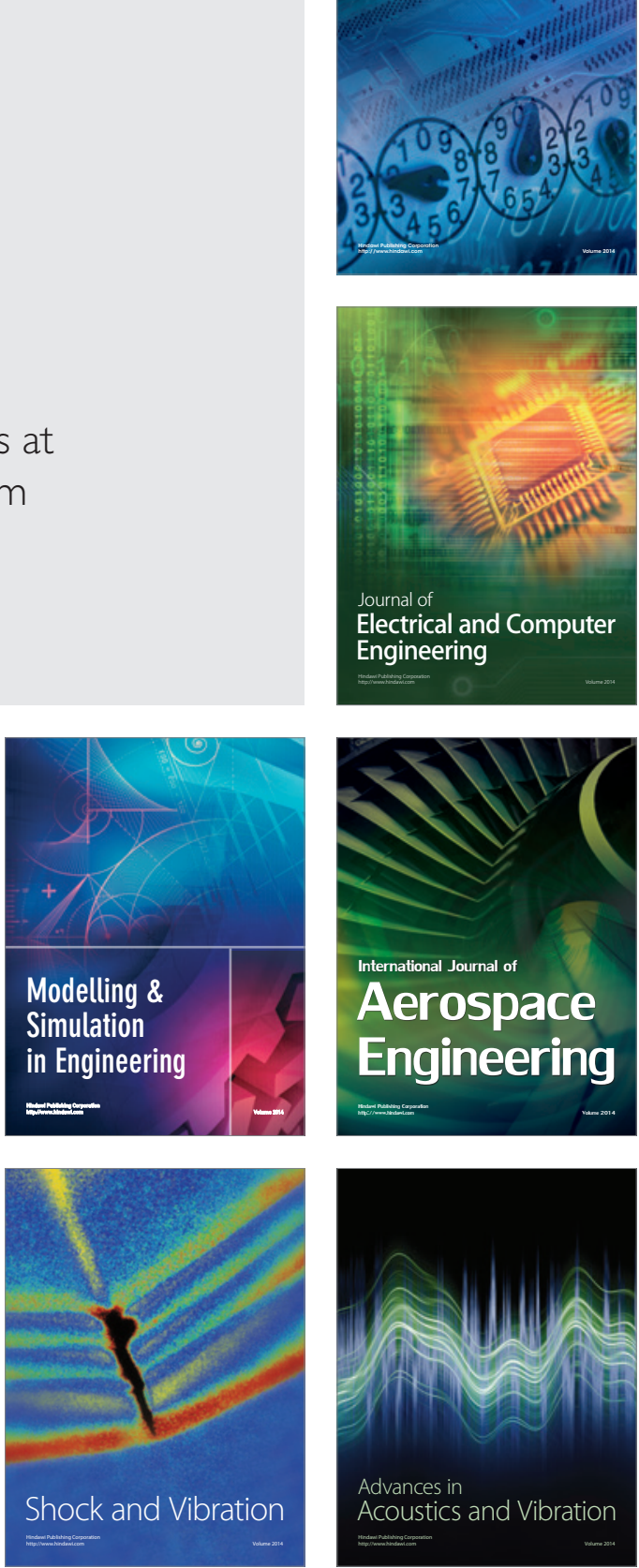